\title{
Percutaneous transluminal dilatation of proximal stenosis of left anterior descending coronary artery in patient with bronchogenic carcinoma ${ }^{\star}$
}

\author{
K NUESCH, Y SCHOLER, R PYLE, A GRÜNTZIG \\ From the Departments of Medicine and Radiology, University Hospital, Zürich
}

SUMMARY The history of a 62-year-old man with a severe stenosis of the left anterior descending artery resulting in an impending infarction and with a bronchogenic carcinoma is reported. In such cases percutaneous transluminal coronary angioplasty offers a new alternative to surgery. In addition, this patient demonstrates a phenomenon in that the stenosis improved even further in the months after the dilatation, with vessel calibre returning to normal.

The indications for coronary bypass surgery in the case of a proximal stenosis of the anterior descending branch of the left coronary artery are still controversial if this is the only lesion, so far as prolongation of life is concerned. ${ }^{2}{ }^{2}$ If the patient is having severe angina, operation should be seriously considered. ${ }^{3}$ The case for operation is more questionable when there is a serious accompanying disease which is expected to shorten the patient's life considerably, as, for instance, coincident bronchogenic carcinoma. In such cases percutaneous transluminal coronary angioplasty offers an alternative to surgery. This method has been available since September 1977, ${ }^{4}$ and has been used in our hospital in more than 100 patients. ${ }^{56}$

This case is being reported for two reasons: (1) to draw attention to this new method of treatment, and (2) because of the phenomenon that the stenosis improved even further in the months after the dilatation, with return of the vessel calibre to normal.

\section{Case report}

A 62-year-old male patient was admitted to the Intensive Care Unit with a four-week history of angina pectoris, and electrocardiographic signs of impending infarction.

The cardiac enzyme levels were normal. Within a few days the electrocardiogram returned to normal, but because the patient complained persistently of pain a coronary angiogram was done. The only abnormality seen on the angiogram was a severe proximal stenosis of the left anterior descending artery (Fig. 1A). At the time of the study two round

* Supported in part by the Swiss National Science Foundation. shadows were noted in the mid-zone of the right lung (Fig. 2), each of which proved, upon needle biopsy, to be a small round cell anaplastic carcinoma.

Although the acute ischaemic episode appeared to have resolved, the patient continued to have severe angina despite treatment with propranolol $(120 \mathrm{mg})$, and isosorbide dinitrate $(60 \mathrm{mg})$, and this was the indication for an attempt at percutaneous transluminal coronary angioplasty.

\section{Method}

Under local anaesthesia, and by the Seldinger technique, a preshaped guiding cathetert was passed from the right femoral artery into the ascending aorta. Through this catheter a double-lumen dilatation catheter was guided into the ostium of the left coronary artery. At its tip the dilatation catheter has a distensible balloon segment of maximum diameter $3 \mathrm{~mm}$. The balloon was introduced fully deflated into the left anterior descending artery, and positioned in the stenosis. It was then inflated with a mixture of 50 per cent contrast medium ( $76 \%$ Urografin) and saline, using an automatic calibrated pump. Three inflations were made using a pressure of 5 atmospheres to obtain maximum distension of the balloon in the stenosis without affecting the normal portion of the artery. Details of the method are described elsewhere. ${ }^{5}$ Dilatation was performed by AG.

\section{Results}

The lumen of the left anterior descending artery + H Schneider, Medintag, Zürich, Switzerland. 

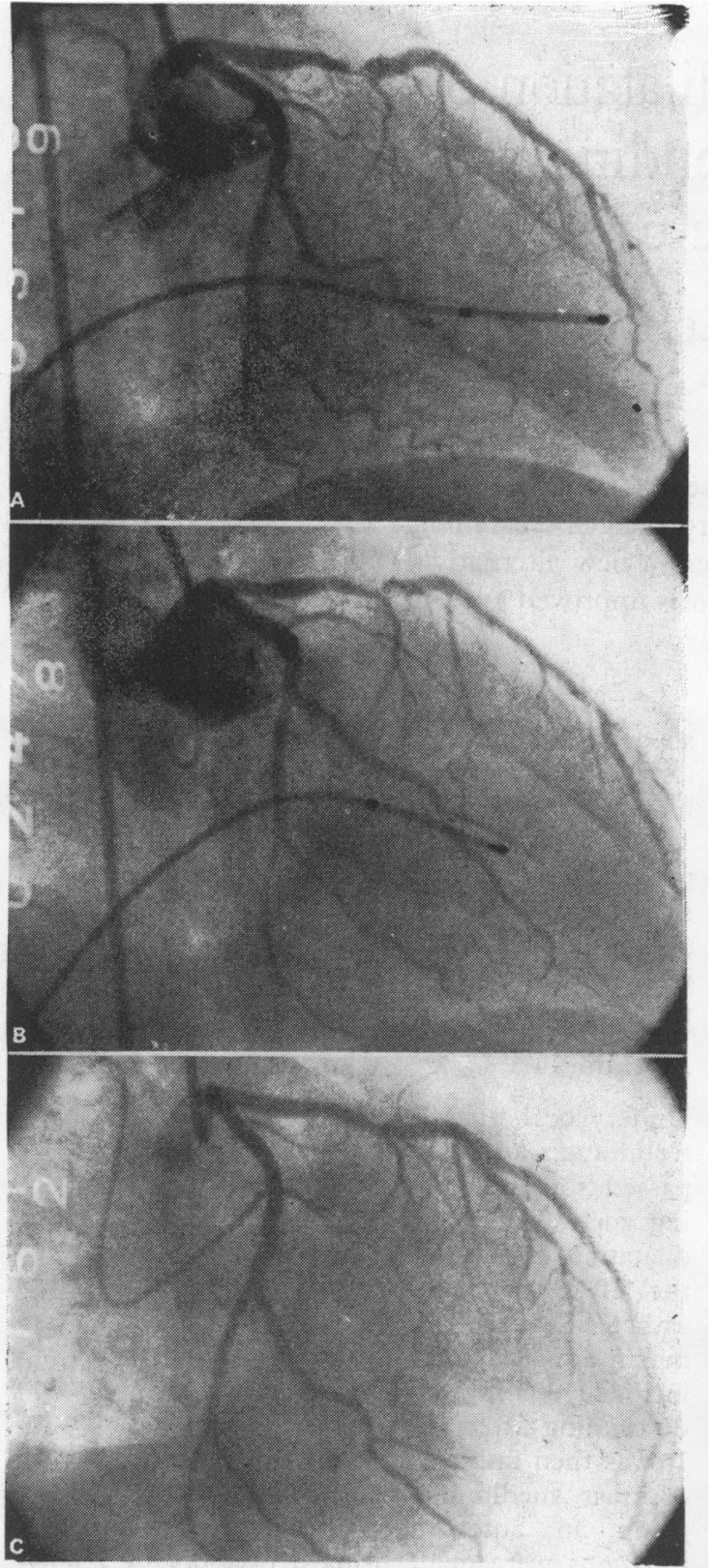

Fig. 1 (A) The severe proximal stenosis of the left anterior descending coronary artery $\left(R A O 30^{\circ}\right.$ oblique projection) (December 1977).

(B) The left anterior descending branch of the coronary artery (LAD) immediately after dilatation. Note residual narrowing of about 50 per cent.

(C) The LAD eight months later showing only slight irregularities of the wall at the site of the previous stenosis (August 1978). was seen to widen after dilatation but the stenosis was not completely eliminated. Angiography immediately after the procedure confirmed that a residual narrowing of about 50 per cent was still present (Fig. 1B). Pressure measurements were taken through the dilating catheter: before, after, distal, and proximal to the stenosis. The distal pressure improved from $31 \mathrm{mmHg}$ to $57 \mathrm{mmHg}$, and the mean pressure gradient across the stenosis fell from $54 \mathrm{mmHg}$ to $27 \mathrm{mmHg}$.

Even though the anatomical result was only a partial improvement, there was a definite amelioration of the clinical condition of the patient, both subjectively and objectively. Before the dilatation, the patient's exercise tolerance measured by bicycle ergometry was 125 watts (expected normal 156 watts), accompanied by $0.3 \mathrm{mV}$ ST segment depression. Two days after the procedure, he was able to maintain a steady state ergometry level of 150 watts without complaint or the appearance of electrocardiographic abnormalities. As an additional non-invasive control study, a thallium-201 myocardial scintigram was done before and after dilatation, the isotope injections being made during stress ergometry and the redistribution imaged four hours later. ${ }^{78}$ Before dilatation there was a triangular, anteroseptal, scintigraphic defect which improved a few days later and was gone at the end of four months. The patient was free of symptoms and it was possible to discontinue all drug treatment.

Because the patient's general condition was so much better, attention was directed to the lung pathology. Thorascopy revealed para-hilar lymph nodes which, upon biopsy, were tumour positive.

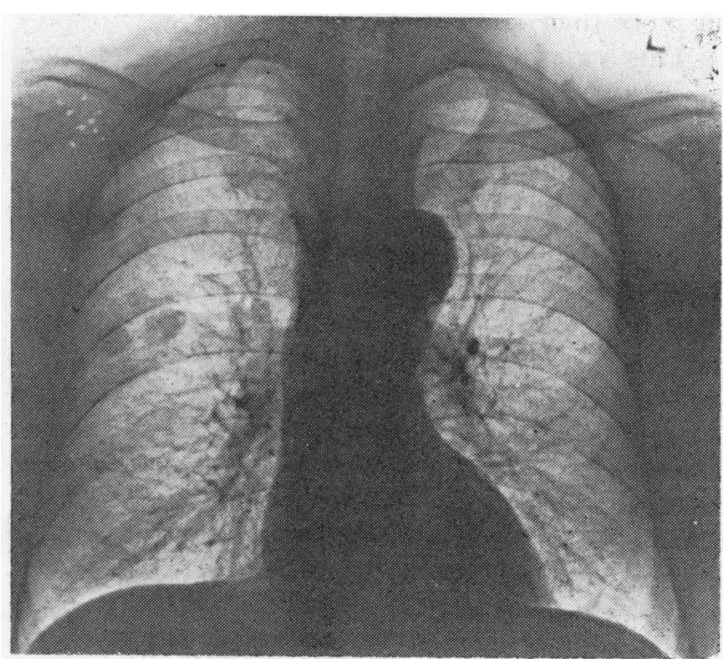

Fig. 2 The two round carcinomatous lesions in the midzone of the right lung. 
He was therefore treated with chemotherapy and radiotherapy.

Eight months after the dilatation the patient returned for a follow-up angiogram which showed a completely patent left anterior descending artery with only slight irregularity of the wall at the site of the previous stenosis (Fig. 1C). The ejection fraction was normal. On clinical examination two years after dilatation the patient remained in NYHA class I without cardiac therapy.

\section{Discussion}

Percutaneous transluminal coronary angioplasty differs from coronary bypass surgery in that it directly increases the blood flow through the stenotic artery without thoracic surgery. ${ }^{5}$ Experience gained in cases treated so far $^{5}$ suggests that the procedure is indicated in patients with a short history of angina (less than 12 months) and with "single vessel disease", that is, no stenosis elsewhere greater than 50 per cent, criteria which this patient fulfilled. The procedure should only be done when a competent surgeon is available, and an operating theatre is in readiness, so that if any complication should arise it can be treated by immediate operation. We have thus only treated those patients so far who, because of their disability, were also candidates for surgery; and they are so informed. Experience has shown that such operations are needed in about 6 per cent of cases. ${ }^{6}$

The patient described above had clinical and anatomical indications for dilatation. Because of his grave prognosis, surgery would only have been done under life-threatening circumstances, but, as seen in the follow-up angiogram, the dilatation was completely successful for him, returning his heart to normal.

From prior angiographic and histopathological studies $^{9} 10$ in the iliac and femoral arteries after transluminal dilatation, it has been shown that some residual stenosis is acceptable and compatible with a clinically adequate haemodynamic result; indeed, the lumen may improve in the months after dilatation as in this case. This phenomenon of further healing after the controlled "injury" of the vessel by the balloon catheter is difficult to reconcile with the usual progressive course of atherosclerosis. Cracking of the plaque, with flushing out of the cholesterol, or mechanical disruption of the atheroma by compression with reabsorption and fibrosis, could be the mechanism ${ }^{11}$; but probably more important is the reintroduction of a normal pulsatile blood flow resulting from restoration of the lumen. This case shows that this continued improvement can be expected in coronary as well as in peripheral arteries, in that the 50 per cent post-dilatation stenosis had completely disappeared eight months later. The possible contribution of spasm can be excluded: the procedure was done under full doses of glyceryl trinitrate and nifedipine, the stenosis was eccentric, and the exercise stress test and the thallium scan improved in the follow-up period.

In this particular case it was possible to solve the patient's acute clinical problem. The normal appearance of the affected vessel eight months later, and the absence of progressive coronary disease elsewhere, make it unlikely that he will experience any angina during the remainder of his life.

\section{References}

1 Kouchoukos NT, Oberman A, Russell RO Jr, Jones WB. Surgical versus medical treatment of occlusive disease confined to the left anterior descending coronary artery. $A m \mathcal{F}$ Cardiol 1975; 35: 836-42.

2 McIntosh HD, Garcia JA. The first decade of aortocoronary bypass grafting, 1967-77. Circulation 1978; 57: 405-31.

3 Cohn LH, Boyden CM, Collins JJ. Improved longterm survival after aortocoronary bypass for advanced coronary artery disease. Am $\mathcal{f}$ Surg 1975; 129: 380-5.

4 Grüntzig AR. Transluminal dilatation of coronaryartery stenosis. Lancet 1978; i: 263.

5 Grüntzig AR, Senning A, Siegenthaler WE. Nonoperative dilatation of coronary-artery stenosis. N Engl f Med 1979; 301: 61-8.

6 Grüntzig AR, Myler R, Stertzer S. Percutaneous transluminal coronary angioplasty (PTCA)-present state of the art (abstract). Circulation 1979; 60: 264.

7 Lütolf UM, Schneider E, Glanzmann Ch, et al. Zur Methodik der Myokardszintigraphie mit Thallium-201: Grenzen zum Pathologischen. Schweiz Med Wochenschr 1977; 107: 1574-7.

8 Hirzel HO, Nüesch K, Grüntzig AR, Horst W, Krayenbühl HP. Thallium-201 exercise scintigraphy after percutaneous transluminal angioplasty of coronary artery stenosis. Med Clin North Am 1980; 64: 163-76.

9 Grüntzig AR. Die perkutane transluminale Rekanalisation chronischer Arterienverschlüsse mit einer neuen Dilatationstechnik. Baden-Baden: G Witzstrock, 1977.

10 Leu HJ, Grüntzig AR. Histopathological aspect of transluminal recanalization. In: Zeitler E, Grüntzig AR, Schoop W, eds. Percutaneous vascular recanalization. Berlin: Springer, 1978: 39-50.

11 Rapaport E. Percutaneous transluminal coronary angioplasty. Circulation 1979; 60: 969-71.

Requests for reprints to Dr A Grüntzig, Department of Medicine, Emory University, School of Medicine, 69 Butler Street, SE, Atlanta, Georgia 30303, USA. 